\title{
MICRO-RAMAN STUDY OF SURFACE ALTERATIONS IN InGaAs AFTER THERMAL ANNEALING TREATMENTS
}

\author{
S. HERNÁNDEZ, R. CUSCÓ, and L. ARTÚS* \\ Institut Jaume Almera (CSIC), C. Solé i Sabarís s. $n$. \\ 08028 Barcelona, Spain \\ *lartus@ija.csic.es \\ N. BLANCO, I. MÁRTIL, and G. GONZÁLEZ-DÍAZ \\ Departamento de Física Aplicada III, Universidad Complutense \\ 28040 Madrid, Spain
}

\begin{abstract}
We present a micro-Raman study of alterations in InGaAs/InP epilayers after rapid thermal annealing. Defects consisting of protruding material with typical dimensions of a few microns can be observed on the surface of the annealed samples. Micro-Raman measurements on these defects show that they consist of $\operatorname{In}_{x} \mathrm{Ga}_{1-x} \mathrm{P}$ alloys, suggesting that phosphorus diffusion from the InP substrate occurs during the RTA cycle. The defect-free region of the epilayer is also altered leading to the formation of an $\operatorname{In}_{1-x} \mathrm{Ga}_{x} \mathrm{As}_{1-y} \mathrm{P}_{y}$ quaternary alloy.
\end{abstract}

\section{Introduction}

$\mathrm{In}_{x} \mathrm{Ga}_{1-x} \mathrm{As}$ epilayers are attracting much interest for applications in optoelectronics in the near infrared and in high electron mobility transistors [1]. For $x=0.53, \operatorname{In}_{x} \mathrm{Ga}_{1-x}$ As is lattice matched to $\mathrm{InP}$, and $\mathrm{In}_{x} \mathrm{Ga}_{1-x}$ As epilayers are usually on $\mathrm{InP}$ substrates. Rapid thermal annealing (RTA) is customarily carried out on these epilayers after ion-beam implantation doping to achieve crystal recovery and the electrical activation of the dopants. Although it is usually assumed that the original $\operatorname{In}_{x} \mathrm{Ga}_{1-x} \mathrm{As}$ crystal is recovered after the RTA step, the complex interplay between thermal diffusion processes and the ion-beam induced damage and/or native crystal defects may lead to significant alterations of the $\operatorname{In}_{x} \mathrm{Ga}_{1-x}$ As epilayer after the RTA. These alterations may, in turn, alter the physical properties of the $\mathrm{In}_{x} \mathrm{Ga}_{1-x} \mathrm{As}$ crystal and be detrimental to the device performance. Therefore, a detailed study of the RTA effects on $\mathrm{In}_{0.53} \mathrm{Ga}_{0.47} \mathrm{As} / \mathrm{InP}$ epilayers is of great technological interest to identify possible sources of device degradation during the fabrication process and thus optimize the final device characteristics.

In this work, we have carried out a study of annealed $\mathrm{In}_{0.53} \mathrm{Ga}_{0.47} \mathrm{As} / \mathrm{InP}$ epilayers which shows that defects associated with phosphorus diffusion develop during the RTA cycles. Structural and stoichiometric alterations of the epilayers have been locally analyzed by means of micro-Raman measurements.

\section{Experimental}

The experiments were carried out on $1.9 \mu \mathrm{m}$ thick $\mathrm{In}_{0.53} \mathrm{Ga}_{0.47}$ As epilayers grown on (100) InP:Fe substrates by metal-organic vapor phase epitaxy, supplied by Epitaxial Products International Ltd. (EPI). One of the samples was implanted with $150 \mathrm{keV} \mathrm{Si}^{+}$to a dose of 
$5 \times 10^{13} \mathrm{~cm}^{-3}$ and another sample was prepared with a $\mathrm{SiN}_{x}: \mathrm{H}$ protective capping covering the InP substrate. RTA cycles were performed on all samples at $905{ }^{\circ} \mathrm{C}$ for $30 \mathrm{~s}$ in an MPT-600 reactor in arsenic-rich ambient, using a graphite susceptor. Examination of the sample surface was carried out using a JEOL 6400 JSM scanning electron microscope at $20 \mathrm{kV}$.

Micro-Raman measurements with a spatial resolution of $\approx 1 \mu \mathrm{m}$ were carried out in backscattering configuration using Jobin-Yvon T64000 spectrometer equipped with a LN2-cooled charge coupled device detector (CCD) and an Olympus microscope. The $514.5 \mathrm{~nm}$ line of an $\mathrm{Ar}^{+}$was used as excitation, and the power on the sample was kept at $\approx$ $5 \times 10^{3} \mathrm{~W} / \mathrm{cm}^{2}$ to avoid heating and photoexcitation effects.

\section{Results and discussion}

Figure 1(a) displays a SEM micrograph of an $\mathrm{In}_{0.53} \mathrm{Ga}_{0.47} \mathrm{As}$ epilayer with substrate capping after RTA at $905{ }^{\circ} \mathrm{C}$ for $30 \mathrm{~s}$. Two types of protruding defects can be observed: large-area octagonal-like defects with a rough surface, and smaller rectangular elongated defects with a crystalline-like appearance and smoother surfaces. Similar structures were observed in the implanted sample, as well as in samples annealed without the protective capping of the substrate. Energy dispersion X-ray analysis indicates the presence of phosphorus in both types of defects. After wet-etching of the annealed sample in a $\mathrm{H}_{2} \mathrm{PO}_{4}$ : $\mathrm{H}_{2} \mathrm{O}_{2}$ solution to remove a surface layer of $\approx 400 \mathrm{~nm}$, faceted crystals were revealed in the center of pits of removed material, as can be seen in Fig. 1(b).
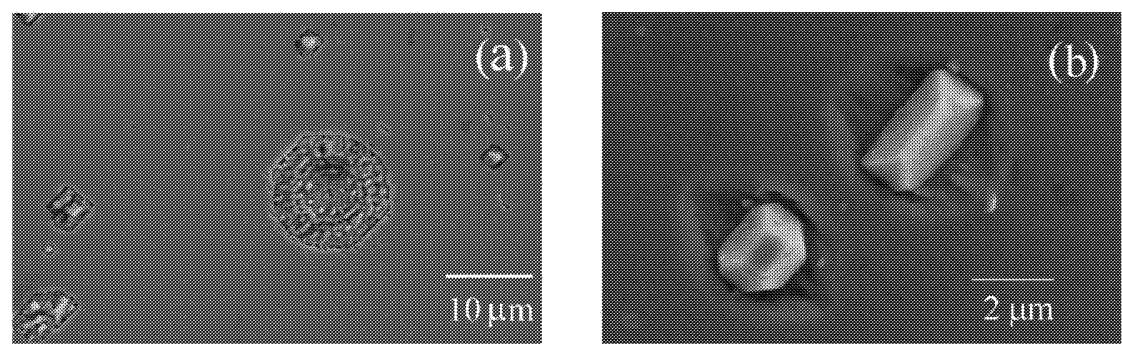

Fig. 1. (a) Scanning electron micrographs of RTA-induced defects on $\operatorname{In}_{0.53} \mathrm{Ga}_{0.47} \mathrm{As}$ epilayers. (b) Facetedcrystal nuclei revealed by wet-etching of the annealed epilayers.

We carried out micro-Raman measurements on the different types of defects observed in Fig. 1. The $x$ (yy) $\bar{x}$ Raman spectra of these defects are shown in Fig. 2(a), where spectrum A corresponds to a large-area octagonal defect, spectrum B was obtained on a rectangular crystalline-like defect, and spectrum $\mathrm{C}$ was recorded from a faceted crystal of the etched sample. All three spectra display similar features, with two dominant peaks in the frequency region between 300 and $400 \mathrm{~cm}^{-1}$ where the optical modes of InP and $\mathrm{GaP}$ occur [2]. This result indicates the formation of the $\operatorname{In}_{x} \mathrm{Ga}_{1-x} \mathrm{P}$ alloy and is consistent with the detection by EDX of a substantial phosphorus concentration in the defects. We assign the most intense peak to the TO mode of an $\operatorname{In}_{x} \mathrm{Ga}_{1-x} \mathrm{P}$ mixed crystal, and the weaker, higher frequency counterpart to the LO modes of the $\operatorname{In}_{x} \mathrm{Ga}_{1-x} \mathrm{P}$ alloy [2]. Using the published data of the frequency dependence on composition of the $\operatorname{In}_{x} \mathrm{Ga}_{1-x} \mathrm{P}$ TO mode [2], we estimate the Ga concentration to be $17 \%, 27 \%$, and $33 \%$ for the defects 
corresponding to spectra $\mathrm{C}, \mathrm{B}$, and $\mathrm{A}$, respectively. The weak broad band observed in the $600-700 \mathrm{~cm}^{-1}$ region corresponds to the second-order optical modes of the $\operatorname{In}_{x} \mathrm{Ga}_{1-x} \mathrm{P}$ alloy, whereas the band observed between 200 and $300 \mathrm{~cm}^{-1}$, in the spectral region of the $\mathrm{In}_{x} \mathrm{Ga}_{1-x}$ As optical modes [5], is due to GaAs-like and InAs-like modes associated with a residual concentration of As in the defects. The very weak structure that can be seen at $\approx$ $430 \mathrm{~cm}^{-1}$, which was previously reported in heavily implanted InP and interpreted as due to P-P vibrations [6], may be indicative of the formation of phosphorus clusters.
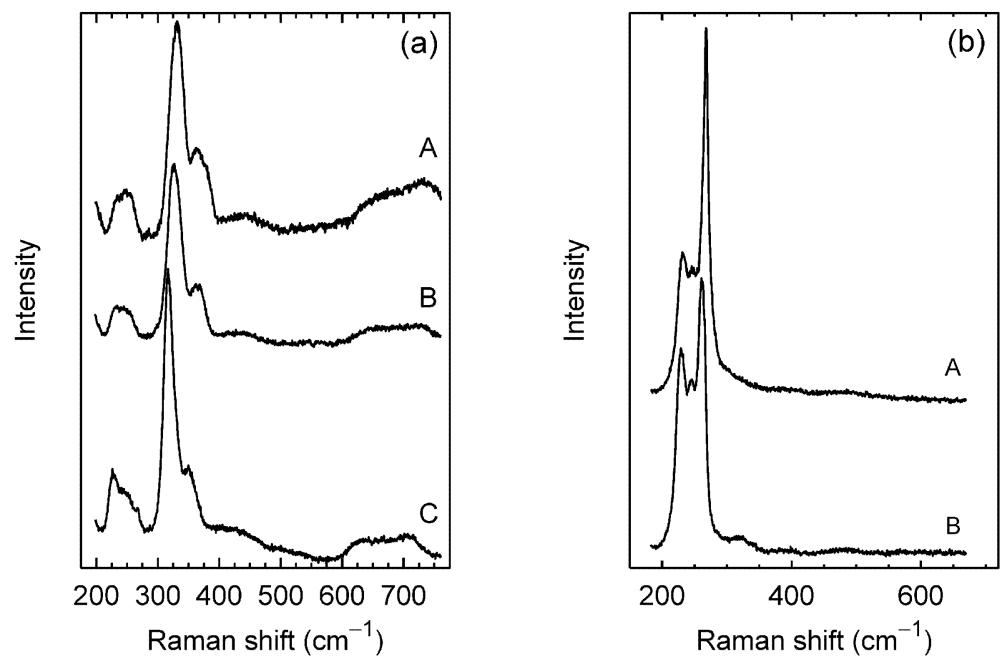

Fig. 2. (a) $x(y y) \bar{x}$ Raman spectra of the different types of defects observed on the $\mathrm{In}_{0.53} \mathrm{Ga}_{0.47} \mathrm{As}$ epilayer after RTA. Spectra A and B correspond, respectively, to the large-area octagonal defect and to the rectangular crystalline-like defects that can be observed in Fig.1 (a). Spectrum C was obtained from the faceted crystal nuclei shown in Fig. 1(b). (b) $x(y z) \bar{x}$ Raman spectra of the as-grown InGaAs/InP epilayer (A) and of the defect-free region of the annealed sample (B).

The large-area octagonal defects exhibit a higher degree of disorder than their rectangular smaller counterparts, as can be seen from the broader peaks of their Raman spectrum in Fig. 2(a). Both the higher growth rate and the higher Ga composition of the large-area defects may contribute to increasing the disorder. By contrast, the faceted crystalline nuclei exposed after etching show a significantly higher degree of crystallinity.

An outstanding feature common to all the Raman spectra of Fig. 2 (a) is the high intensity of the InGaP TO mode, which is forbidden in backscattering from a (100) face. The observation of a strong TO mode can be explained by the fact that, as can be seen in Fig. 1(b), the nuclei of the phosphorus-rich defects consist of faceted crystals that present a large cross-section of (111) and (110) faces to the incident laser beam.

Figure 2(b) displays the $x(y z) \bar{x}$ Raman spectra of the defect-free region of the epilayer. The $\mathrm{In}_{0.53} \mathrm{Ga}_{0.47} \mathrm{As}$ GaAs-like LO mode is observed as a sharp intense peak in the spectrum of the as-grown sample (A), whereas the InAs-like mode is detected as a weak peak at $233 \mathrm{~cm}^{-1}$ [5]. The peak at $244 \mathrm{~cm}^{-1}$ was previously identified as a disorderrelated mode [5]. In the spectrum of the annealed sample (B), an additional weak peak clearly emerges at $\approx 325 \mathrm{~cm}^{-1}$ and both the GaAs-like and the InAs-like LO modes show a sizable shift to lower frequencies. These changes indicate the incorporation of phosphorus in the epilayer leading to the formation of the $\operatorname{In}_{1-x} \mathrm{Ga}_{x} \mathrm{As}_{1-y} \mathrm{P}_{y}$ quaternary 
compound lattice matched to InP. In fact, the peak at $\approx 325 \mathrm{~cm}^{-1}$ can be assigned to the InP-like LO mode of an $\operatorname{In}_{1-x} \mathrm{Ga}_{x} \mathrm{As}_{1-y} \mathrm{P}_{y}$ alloy with low $\mathrm{P}$ composition, and the downward frequency shift of the GaAs- and InAs-like modes is consistent with the quaternary alloy formation [7]. From the observed shift of the GaAs-like LO mode, we estimate that the phosphorus concentration of the quaternary alloy is less than 5\% [7].

\section{Conclusions}

RTA cycles, which are widely used in device fabrication subsequently to ion-beam implantation, induce alterations in $\mathrm{In}_{0.53} \mathrm{Ga}_{0.47} \mathrm{As} / \mathrm{InP}$ epilayers due to phosphorus diffusion from the InP substrate. These alterations have been observed in all the annealed samples, either implanted and unimplanted, and are strongest in samples with a substrate protective capping, which indicates that they arise from phosphorus outdiffusion from the InP substrate during RTA. Since all these alterations may be deleterious to the device performance, any $\operatorname{In}_{x} \mathrm{Ga}_{1-x} \mathrm{P} / \mathrm{InP}$ epilayer processing that involves thermal annealing steps should be carefully monitored.

\section{Acknowledgements}

This work was partially supported by DGICYT grant PB97-1254 and by CICYT grant TIC-98/0740. One of us (S. H.) acknowledges support from Departament d'Universitats i Recerca de la Generalitat de Catalunya.

\section{References}

1. S. Koumetz, J. Marcon, K. Ketata, C. Dubon-Chevalier, P. Launay, J. L. Benchimol, Appl. Phys. Lett., 67, (1995), 2161-2163.

2. R. Beserman, C. Hirlimann, M. Balkanski, J. Chevallier, Solid State Commun., 20, (1976), 485-487.

3. L. Artús, R. Cuscó, J. Ibáñez, N. Blanco, G. González-Díaz, Phys. Rev. B., 60, (1999), 5456-5463.

4. B. Jusserand, S. Slempkes, Solid State Commun., 49, (1984), 95-98.

5. J. P. Estrera, P. D. Stevens, R. Glosser, W. M. Duncan, Y. C. Kao, H. Y. Liu, E. A. Beam III, Appl. Phys. Lett., 61, (1992), 1927-1929.

6. R. Cuscó, G. Talamás, L. Artús, J. M. Martin, G. González-Díaz, J. Appl. Phys., 79, (1996), 3927-3929.

7. A. Pinczuk, J. M. Worlock, R. E. Nahory, M. A. Pollack, Appl. Phys. Lett., 33, (1978), 461-463. 
Copyright $\odot 2003$ EBSCO Publishing 
Copyright $\odot 2003$ EBSCO Publishing 
Copyright of International Journal of Modern Physics B: Condensed Matter Physics; Statistical Physics; Applied Physics is the property of World Scientific Publishing Company and its content may not be copied or emailed to multiple sites or posted to a listserv without the copyright holder's express written permission. However, users may print, download, or email articles for individual use. 